\title{
TRANSITION TO «GREEN» ECONOMY IN RUSSIA: CURRENT AND LONG-TERM CHALLENGES
}

\author{
Irina Makarova* \\ Kazan Federal University, Naberezhnye Chelny, Russia \\ Rifat Khabibullin \\ Kazan (Volga Region) Federal University, Naberezhnye Chelny, Russia \\ Gennady Mavrin \\ Kazan (Volga Region) Federal University, Naberezhnye Chelny, Russia \\ Dmitry Zhdanov \\ Kazan (Volga Region) Federal University, Naberezhnye Chelny, Russia \\ Vadim Mavrin \\ Kazan (Volga Region) Federal University, Naberezhnye Chelny, Russia \\ Eduard Belyaev \\ Kazan (Volga Region) Federal University, Naberezhnye Chelny, Russia \\ IInar Suleymanov \\ Kazan (Volga Region) Federal University, Naberezhnye Chelny, Russia
}

Nowadays, many believe that there is no way to ecological stability other than transition to "environmentally oriented economy». In urban areas, the main sources of pollutants are industrial enterprises and automobile transport. To reduce the adverse environmental impacts one needs special methods of air quality control. Specifically, research in this field is aimed at developing of control systems for the city transport in order to predict the environmental response to changing traffic parameters and take appropriate measures to improve the situation. In this work it is demonstrated how the method of transport system control, based on simulation modeling, has been implemented. The optimization experiment has been performed on a simulation model adjusting the parameters of parts of a city road network for adequate decision making. Model experimenting has made it possible to establish the optimal traffic density and average current rates, without exceeding the pollution quotas, and calculate the consequences of changing in the number of vehicle car fleet on city roads. The experiment was carried out in the city of Naberezhnye Chelny, Russia.

Key words: Air, Road transport, Intensity, Maximum allowable concentration, Motorway

\section{INTRODUCTION}

Notwithstanding the benefits of recent technological and industrial advances, it has been increasingly emphasized that the ever growing volumes of mined and digested mineral resources promote the environment pollution, which has become a global challenge.

Although all working under the premise that "green" economy is to be low-carbon, efficient in resource utilization, and socially inclusive, the European states have different priorities. Thus, while the EEA states focus on sustainable consumption and production (SCP), and innovation, the priorities of Eastern Europe, the Caucasus, Central Asia, and Russia are management development and power production [03].
The quality of management is all-important and has been extensively researched because it affects the stability of systems, notwithstanding their size or parameters, but mostly the major systems such as organizational, technical and social-economic ones.

Although being based on different methods, good management of today has opted for simulation. The decision-making process incorporates numerous internal parameters and subsystems, as well as external impacts of which many are stochastic and processing of much information by using sophisticated algorithms. Moreover, since processes in large systems are long in time, they cannot be examined under actual conditions. The quality of decisions depends on both 
the quality of initial information and adequacy of algorithms for its interpretation, and is controlled by consistency in behaviour of modeled and real processes.

Transition to "green" economy is unique for each country, being affected by various interrelated factors. However, the main trends and challenges have been shaped by global processes and are relevant for both developed and developing countries. One of those is urbanization, which is an objective process triggered by social demands, modes of production, and character of the social system. As a consequence, a precipitous growth of urban population, especially in recent decades, has depleted the reproductive capacity of the environment in major cities.

Urban growth transforms the landscape, land and water resources; massive industrial and communal waste affects the aquatic and terrestrial ecosystems. The urbanized mankind is faced with vulnerability of urban systems, migration and concentration of population, low quality of habitat, loss of fertile land, and necessity of waste disposal. A large city modifies almost all components of natural environment - the atmosphere, vegetation, soil, topography, drainage, ground water, soil, and even the climate.

Among the most environment-offending industries are nonferrous and ferrous metallurgy, chemical, petrochemical, woodworking, and pulp and paper production. Much has been said about the deplorable state of the environment on areas accommodating industrial enterprises emitting into the atmosphere such toxic substances as benzopyrene, different hydrocarbons, phenols, and heavy metals.

In large cities, a significant contribution to atmospheric pollution with sulphur dioxide, nitrogen and carbon oxides, and industrial dust comes from the motor transport. As stated in a report of the World Health Organization on traffic security, by promoting transfer of goods and people, road transportation benefits both countries and individuals. It facilitates access to workplaces, economic markets, education, recreation and entertainment centers, and also health services which, in turn, positively affects the public health, both directly and indirectly. Nevertheless, growing motor traffic inevitably affects the human health by causing road and transport traumatism, respiratory diseases and diseases caused by physical inactivity.
Other harmful economic, social and ecological consequences of motor transportation include air pollution, emission of hotbed gases, consumption of nonrestorable resources, household inconveniences caused by adjacent highways, and noise. [02]

Engine exhaust gas also contains much lead and ozone adversely affecting the health of urban residents. For instance, sulfur dioxide damages the respiratory system, causing coughing, chest pain, shortness of breath, and airway constriction. Engine exhaust contributes to increasing of lead concentration in atmosphere, proportionally to traffic intensity. Lead gets into surface and ground water. From soil it is actively accumulated by vegetation so that its contents in roadside plants are 100 times higher than that in plants growing on relatively unpolluted areas. Such plants may be poisonous if used as food.

Another urban problem is degradation of green space caused by air pollution. In Moscow, about $20 \%$ of trees and shrubs are damaged by chlorosis and necrosis. Sound pollution in cities is promoted by ever increasing road traffic, particularly in narrow streets, and inadequate amenities in isolated residential districts and squares.

Says Vladimir Drobnyak, ECOSOC (Challenges and Opportunities for Sustainable Urbanization) Vice-President in follow-up to the meeting of the Segment of Integration of Economic and Social Council on 27-29 May 2014 [01]: "Cities are emerging as a leading force in mainstreaming environmental responsibility and combating climate change through integrating green technologies in sustainable infrastructure, reducing the carbon footprint of urban metropolises through innovative measures of reducing pollution and generating innovative solutions to reduce energy consumption. Adopting modes of public transportation that utilize alternative sources of energy such as electricity, utilizing biowaste in heating systems of municipal buildings, applying off-grid renewable energy systems such as solar energy panels, or integrating information and communication technologies (ICTs) in the management of traffic congestion are examples of innovative solutions that can aid in the effort to reducing greenhouse gas emissions and enhancing environmental resiliency of cities [01] ". Considering the public concern regarding the sustainability of urban territories and increasing human migration to cities worldwide, there has 
been developed a project concept of a system of city management taking into account both the mobility needs of population and environmental factors [06].

\section{MANAGEMENT OF TRAFFIC INFRASTRUCTURE}

The stability of traffic infrastructure in metropolitan cities depends on the performance of its subsystems, including the reliability of communication therein, which in turn largely depends on management efficiency. Nowadays, controlling of large systems is supported by special decision-making arrangements, expert systems and information management systems. These systems assist in tackling of both strategic and tactical tasks. By wisely addressing these issues a city may more successfully deal with its economic and social problems by improving the transport service for the population and reducing the negative impact of the transport complex on the environment.

Since the quality of decisions in large systems depends on the quality of information, its adequate analysis, and efficient analytical tools for large data arrays, it needs Decision Support Systems (DSS) combining the features and capabilities of information and database management systems. In DSS, analysis and selection of recommendations ensue as a result of information search, data mining and retrieval from databases, reasoning based on precedents, simulation modeling, evolutionary computation and genetic algorithms, neural networks, situational analysis, cognitive modeling, etc. If a DSS incorporates artificial intelligence techniques, it is called an intellectual DSS. A conceptual diagram of a DSS is presented in Figure 1.

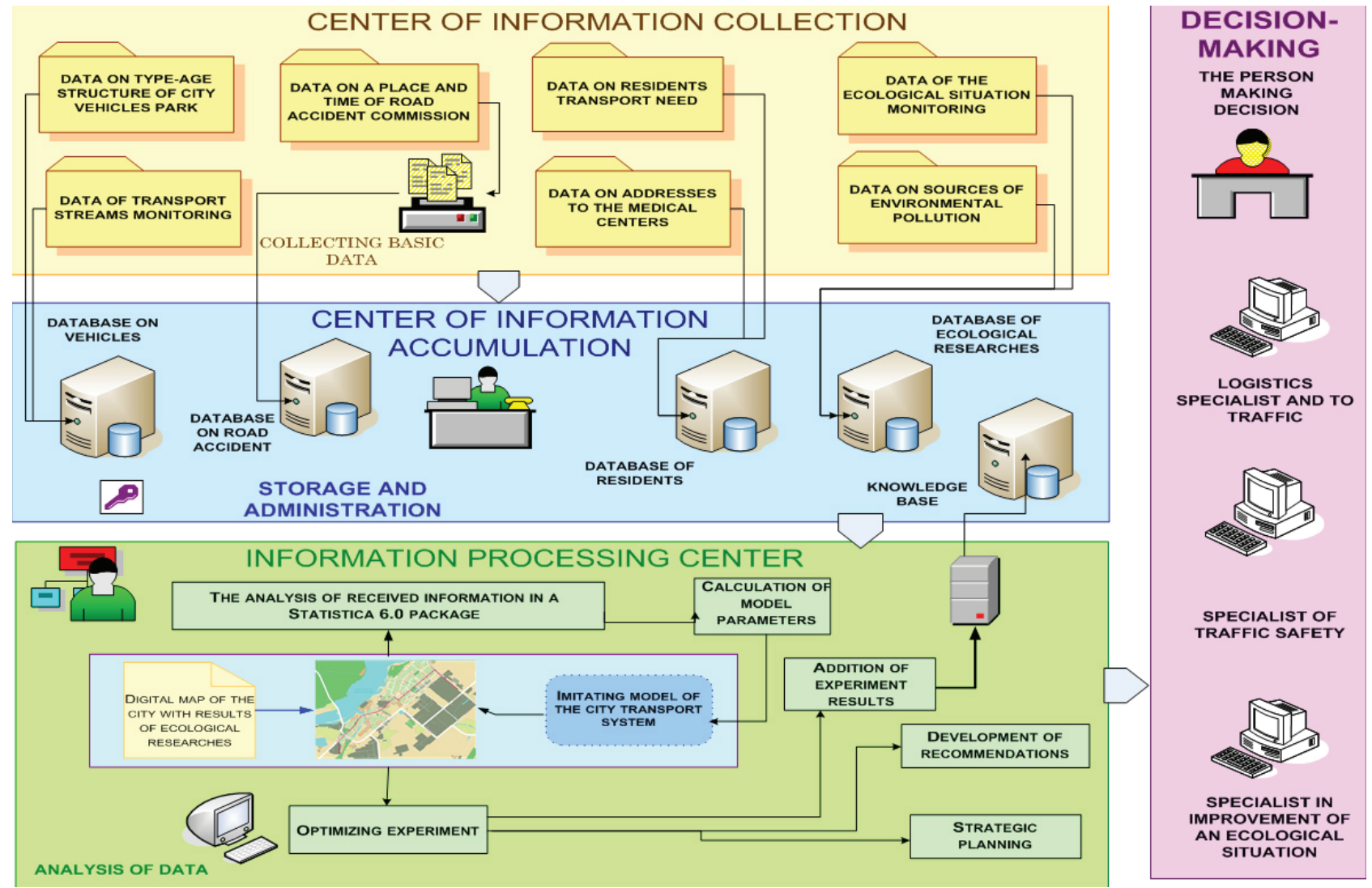

Figure 1: The conceptual scheme of DSS

The DSS are designed to suit both the tasks to be solved, the available data, information and knowledge, and also the system users. There are three main parts in a DSS:

1. Data system for collection and storage of information obtained from internal and external sources.
2. A dialogue system permitting the user to specify the desired data and select a pathway for their treatment.

3. A system of models incorporating ideas, algorithms and procedures for data processing and analysis. When selecting data, the user is based on his/her experience, knowledge 
of the situation and their own needs. Data processing incorporates different procedures ranging from simple summation to statistical analysis and nonlinear optimization.

In designing of a DSS, focus is made on its intellectual core, i.e. the simulation model. It is simulation modeling that makes possible qualitative analysis of processes, to explore the effects of any changes and select a variant satisfying all the set limits, and obtain optimal parameters. [05]

The software, developed for these purposes, enables one to construct models that reflect real-life processes whereupon to conduct virtual experiments specifying the model time. The process can be researched both in a single test and in a number of tests allowing selecting the optimal process parameters. The results will depend on their random nature.

The effect here is threefold. Economy-wise, the intelligent transport systems will assist in diminishing of transportation costs owing to optimized traffic routes and better utilization of vehicles. The environmental effect consists in reducing of pollution. Social improvements will be represented by better air quality and diminished rates of respiratory diseases.

\section{MANAGEMENT OF VEHICLE FLEET}

Since optimization for the transport system can be achieved in two ways, i.e. by regulating the traffic current density and making vehicles more environmentally friendly, relevant research is being conducted in two directions. Thus, traffic can be controlled by resorting to fiscal measures, such as banning on entrance to busy areas, traffic control, etc, and also through a more efficient use of the road network capacity, in other words, by increasing the occupancy rate of vehicles, encouraging the use of more capacious vehicles, and total renovating of the vehicle fleet.

Statistic analysis has revealed that large car parks are more responsible for the environment pollution than personal vehicles due to greater annual mileage of the former. While a personal car runs about 12000 miles/year, an average motor van may run as many as 23000 miles/year [10]. In this work, to demonstrate the potential benefits from transport fleet management, we decided to analyze the subsystem of public passenger vehicles from car parks (Figure 2).

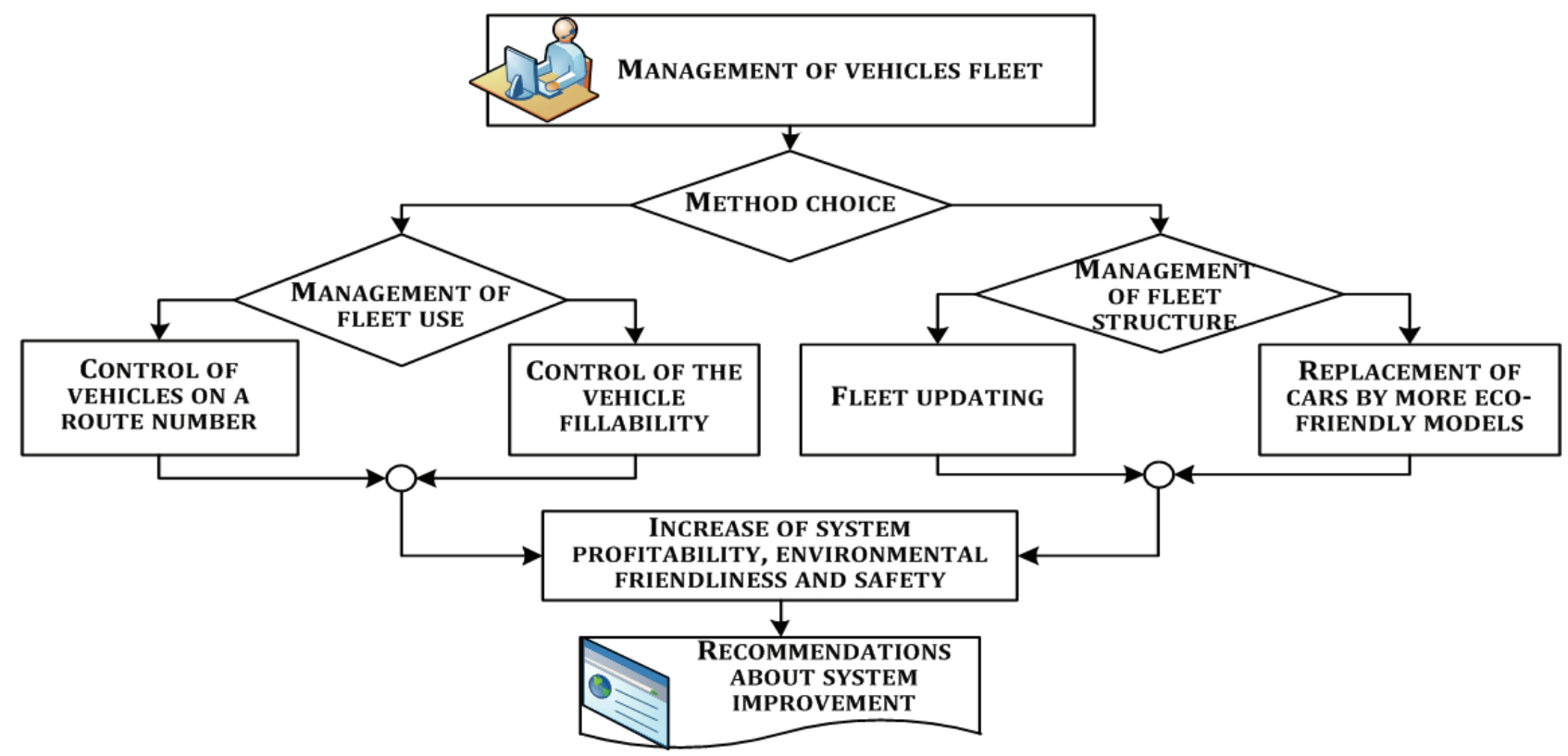

Figure 2: Management methods of vehicles fleet

Firstly, because replacement of vehicles in car parks occurs more often than with individual owners. Besides, park owners are easier motivated to use cars more efficiently.

\section{DATA MANAGEMENT IN A DECISION-MAKING SUPPORT SYSTEM}

Since decisions are made proceeding from real data about an object, both analysis and ensuing strategic decisions require aggregated information stored in a specially created Data Warehouse 
(DW). The role of DW consists in integrating, updating and coordinating of operational information from dissimilar sources in order to form a consistent view on the object in whole. Data

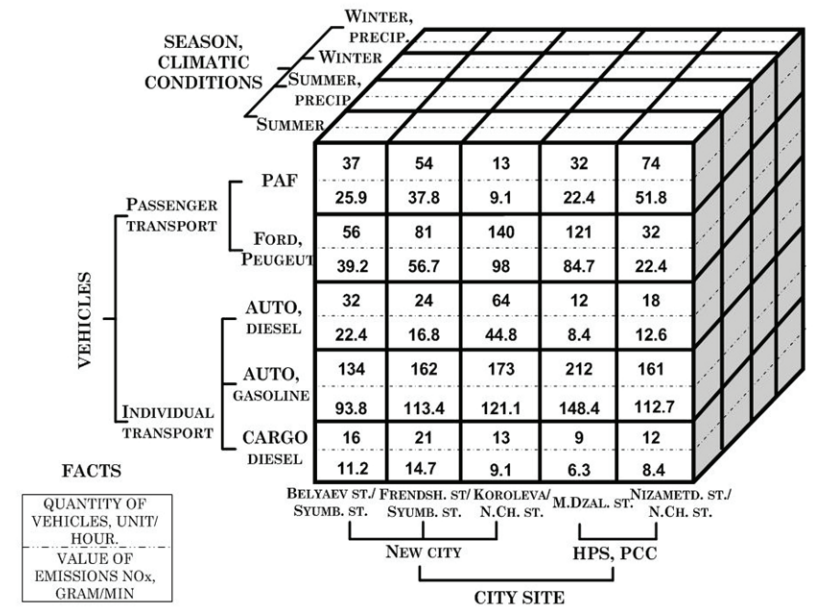

Warehouses contain information collected from several operative databases of On-Line Transaction Processing systems (OLTP) (Figure 3).

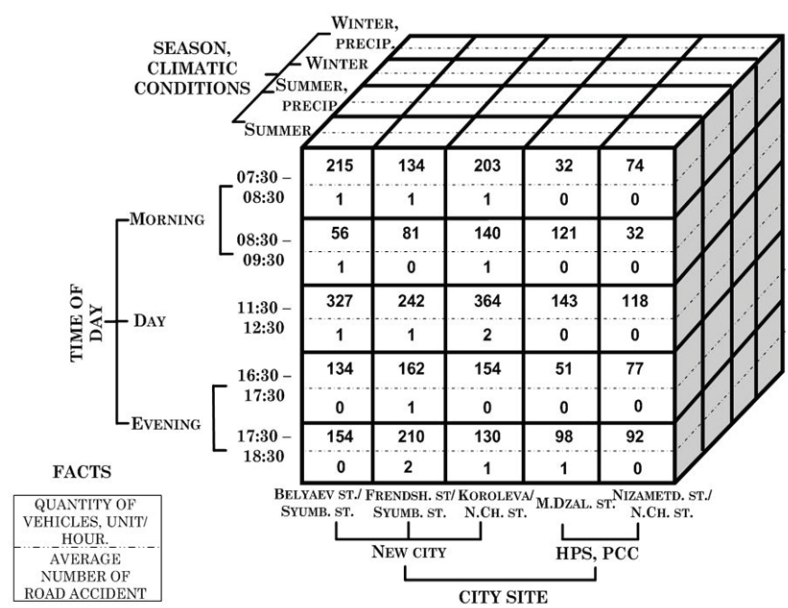

Figure 3: Presentation of data in the form of OLAP-cube a) dimension "transport type", b) measurement "time of day"

A multidimensional intellectual data model is installed in the traffic control centre for collecting, storing and formalizing of road network parameters.

The analytical cube has the following parameters:

1. Model, make and type of a car engine.

2. Season of the year.

3. Time of the day.

4. Average useful life of passing cars.

5. Traffic intensity.

6. Movement direction.

7. Average speed of traffic current.

8. Length of traffic jams and number of stops for public transport.

9. Total number of cars passing per hour.

10.Value of emissions to atmosphere (CO, NOx, etc.).

11. Number of road accidents during the observation period.

For correct simulation of real-life situations it is necessary to have immediate information coming to the Control Centre in the real-time mode from different sources, such as servers of municipal enterprises and units for on-line monitoring of road situations (GPS/GLONASS systems).

The operation algorithm includes:

1. Data acquisition in the form of a flat chart or results of SQL inquiry.
2. Data caching and conversion to a multidimensional cube.

3. Imaging of the constructed cube by means of a cross chart or diagrams, etc.

In general, one cube may be connected to an arbitrary amount of mappings.

The advantage of this technology lies in the fact that applications for the multidimensional analysis meet the requirements of the so-called FASMI test (Fast Analysis of Shared Multidimensional Information) including the following parameters:

I. Fast, i.e. fast response of the system (not more than 5 seconds),

II. Analysis - full-functional analysis achieved in the most convenient way,

III. Shared - multiuser access, protection of information, etc.,

IV. Multidimensional - a multidimensional conceptual data presentation as cubes with hierarchical measurements,

V. Information - access to data in required volume, wherever it is necessary.

Storing of information as an OLAP cube and its subsequent processing allows estimating more accurately the dynamics of street network parameters (number of vehicles, road section, season of the year, average speed, availability of traffic lights, etc.). Packages of formalized data are continuously transferred to the simulation system for changing of model parameters. By analyzing the information of city transport sys- 
tem parameters varying within a day, day of the week, and month of the year, one can predict similar road situations. Furthermore, modeling of workarounds with changing system parameters facilitates selecting of the optimal ones and building a knowledge base of best solutions at established traffic and environment parameters. Such databases are used for on-line making of management decisions in the case of emergency.

\section{RESULTS AND DISCUSSION}

\section{Monitoring of urban airshed}

In the city of Naberezhnye Chelny, Russia, motor vehicles are the main pollutants of the environment, all major stationary sources of pollution being located outside or along the city boundary. Spatial planning of the city was performed with respect to the natural landscape: the city faces the expanses of the Nizhnekamsk water storage basin, the Shelninsky Bay, and forests on their shores. The city planning pattern represents an open linear structure and land use of the "classical" type, with parallel locating of industrial, residential, and suburban recreation areas. The transport frame of the city is made up by longitudinal highways connecting the residential areas, so that the road and street network is rectangular. The biggest longitudinal thoroughfare incorporates Musa Jalil, Naberezhnjchelninsky, and Mira Avenues (Figure 4). [13]

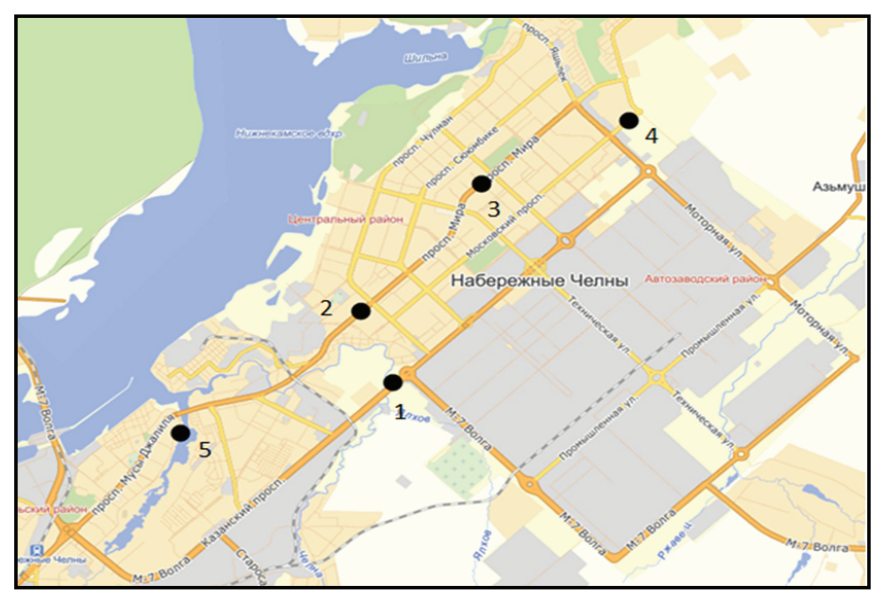

Figure 4: Plan-scheme of the location of points of the control of atmospheric air within the sanitation gap road in Naberezhnye Chelny

In order to determine the level of atmospheric pollution and the major offending sites in $\mathrm{Na}$ berezhnye Chelny, we calculated vehicles emissions by using the known methods.[08; 26; 27]. These consisted in calculating of the traffic intensity during one year through field surveying on the highways. As a result, there were examined the traffic currents on 43 highways with 154 protocols of vehicle current composition and intensity drawn for each highway section.[08; 04; 09]

Analysis of the protocol data has revealed that vehicles in residential areas are mostly represented by passenger cars (85-95\%), whereas the share of freight transport does not exceed 3-4 \%.

On industrial areas and roads of federal and republican importance, the share of freight transport in the traffic may achieve $10-20 \%$. Accordingly, the passenger cars contribution to the total traffic intensity is $60-80 \%$.

According to the result of field surveying of the structure and intensity of transport current, the load on the city highways is unbalanced, with peaks of intensity at different motorways varying within a day.

For the industrial zone, the traffic current is the most intensive between 6:30 and 8:00 am and 04:30 to $06: 00 \mathrm{pm}$, that is, before the workday and soon after it is over. During the rest of the day, the highways are loaded but slightly. The same traffic intensity was observed in the direction of the industrial area (Vahitovskiy, Avtozavodskoy, and Druzhby Narodov avenues, and Koroleva St.).

Having analyzed the road layout, the purpose of motor roads, and information about the traffic load, we selected the following 5 road portions for instrumental measurement of ambient air pollution on the following roadside clear zones:

1) Orlovskoe Koltso (part of M-7 federal highway, site №1).

2) Naberezhnochelninskiy avenue (at its junction with Akademika Koroleva St., site №2).

3) Mira Avenue (to the junction with Vakhitova Avenue, site №3).

4) Adelya Kutuya Street (Yashlek housing estate, site №4).

5) Naberezhnaya G. Tukaya (opposite the apartment block No 10/64, site №5)

Sampling of atmospheric air was carried out in the immediate vicinity of roads, mainly from downwind, during the morning and evening rush hours and, on the Orlovskoe Koltso, during the lunch time.

For each site there were obtained 2 duplicate samples, so that the total number of samples was 600 . Both the initial working solutions (600) and 300 blank solutions were prepared for analysis 
at a chromatograph with a photoionization detector and photometer. Analysis for the presence of carbon monoxide has required the obtaining and processing of more than 300 chromatograms. According to the findings of instrumental measurement, the following dependencies were established:

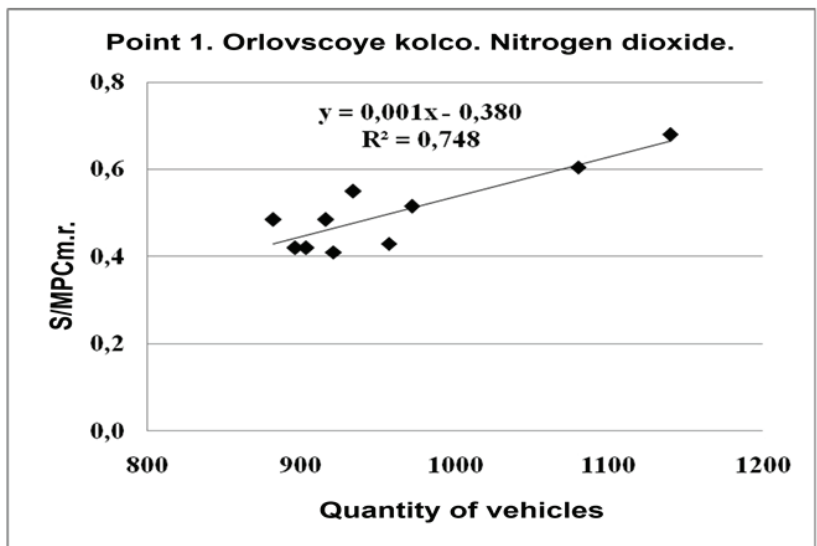

1) Traffic intensity vs pollutant concentration (Figure 5);

2) Atmospheric air temperature vs pollutant concentration (Figure 6);

3) Wind speed vs pollutant concentration (Figure 7).

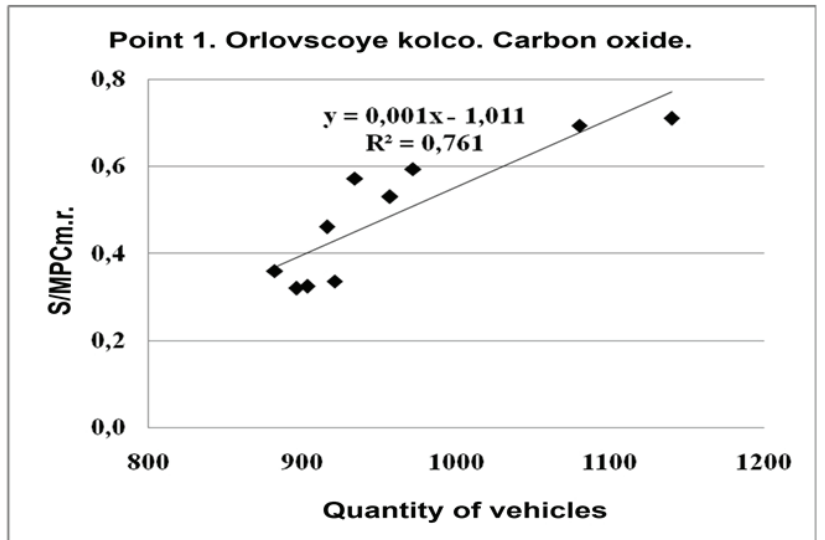

Figure 5: The dependence of the coefficient of concentration on the intensity of the movement

It should be noted that relationships with a correlation coefficient of 0.74 and higher were obtained for concentration coefficients from 0.3 upwards for nitrogen oxides, sulfur dioxide and carbon monoxide, and were found to depend on

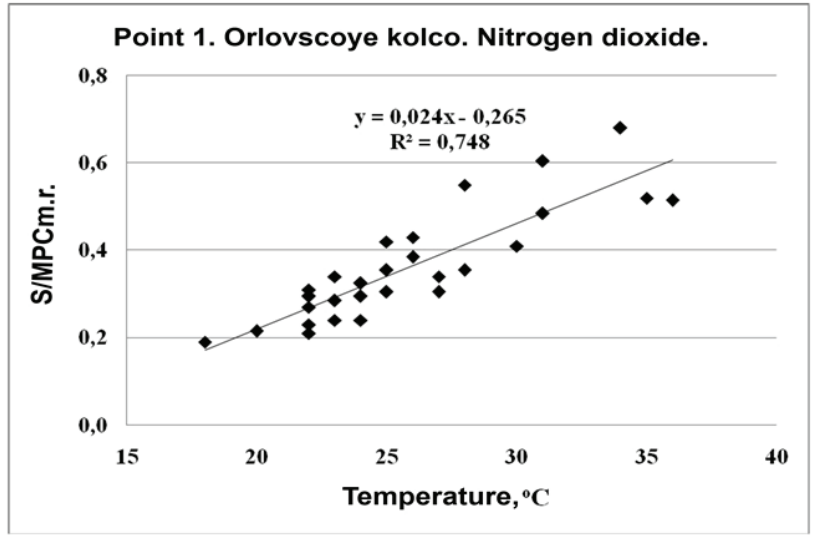

transport intensity and air temperature (Figure 5). Moreover, at regularly high C/ACLms values there was observed a noticeable correlation between the wind speed and nitrogen and carbon oxide concentrations.

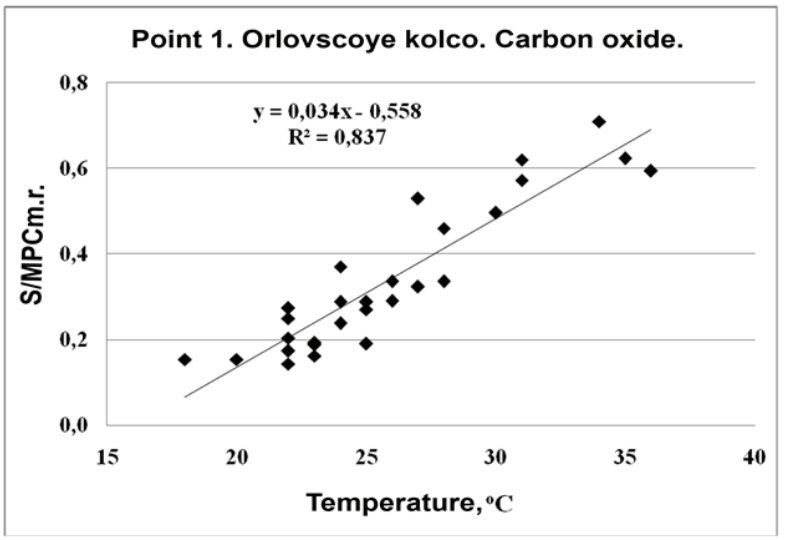

Figure 6: The dependence of the concentration coefficient on temperature of air
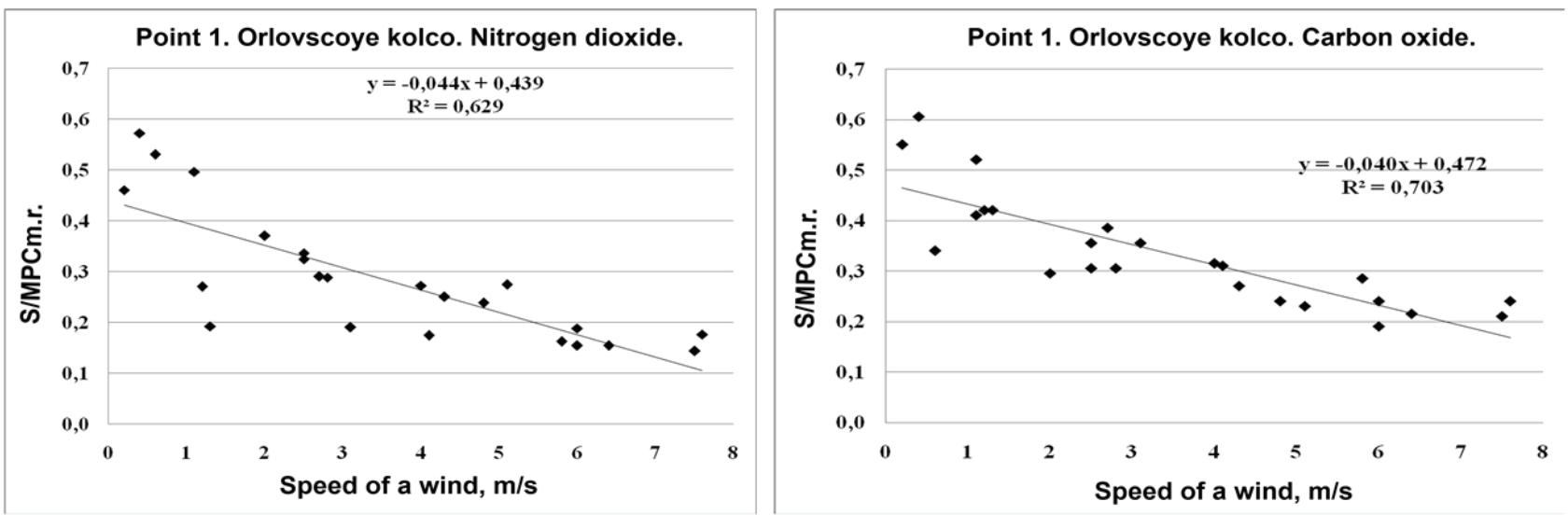

Figure 7: The dependence of the concentration coefficient on the wind speed 
Systematization of the results of instrumental measurements, taking into account the wind direction on urban areas, has proved impossible due to volatility of wind direction.

\section{Simulation modeling of the city transport system}

Using the maps of pollutant dispersion from stationary sources, derived as a result of field observations, we highlighted the problem areas, one of which is a complex junction formed by intersecting Mira, Druzhba Narodov and Syuyumbike Avenues (Figure 8).

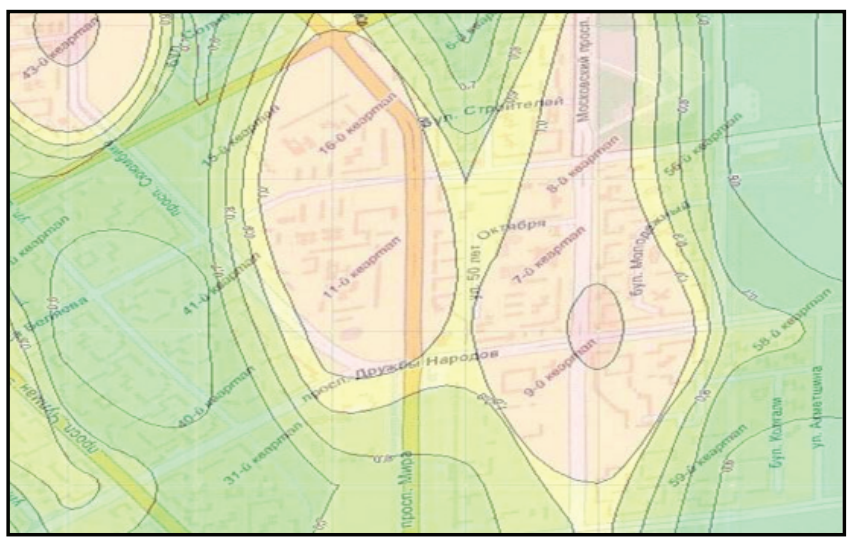

Figure 8: Decoupling scheme simulated road network
For more detailed analysis of the area, we constructed a simulation model using the AnyLogic software (Russia). The following factors were taken into account:

I. Geometry of the road network portion;

II. Traffic density;

III. Intensity of pedestrian traffic along traffic lanes;

IV. Pollutants actually emitted by motor vehicles and emission quotas;

$V$. Modes of traffic lights operation at road portions preceding and following the portion being analyzed.

A constraint for the model was the value of the emission quota that was not to be exceeded:

$Q_{\text {aem. }}=\frac{M_{L i}+M_{\Pi i}+M_{n p .}}{M_{\kappa e .}} \leq 1$

A structural scheme of the model of traffic current organization is presented in Figure 9. The scheme draws on both the road library items (Road Network, Car Source, Car Dispose, CarMoveTo) and the main library items (Hold, Delay Queue, SelectOutput).

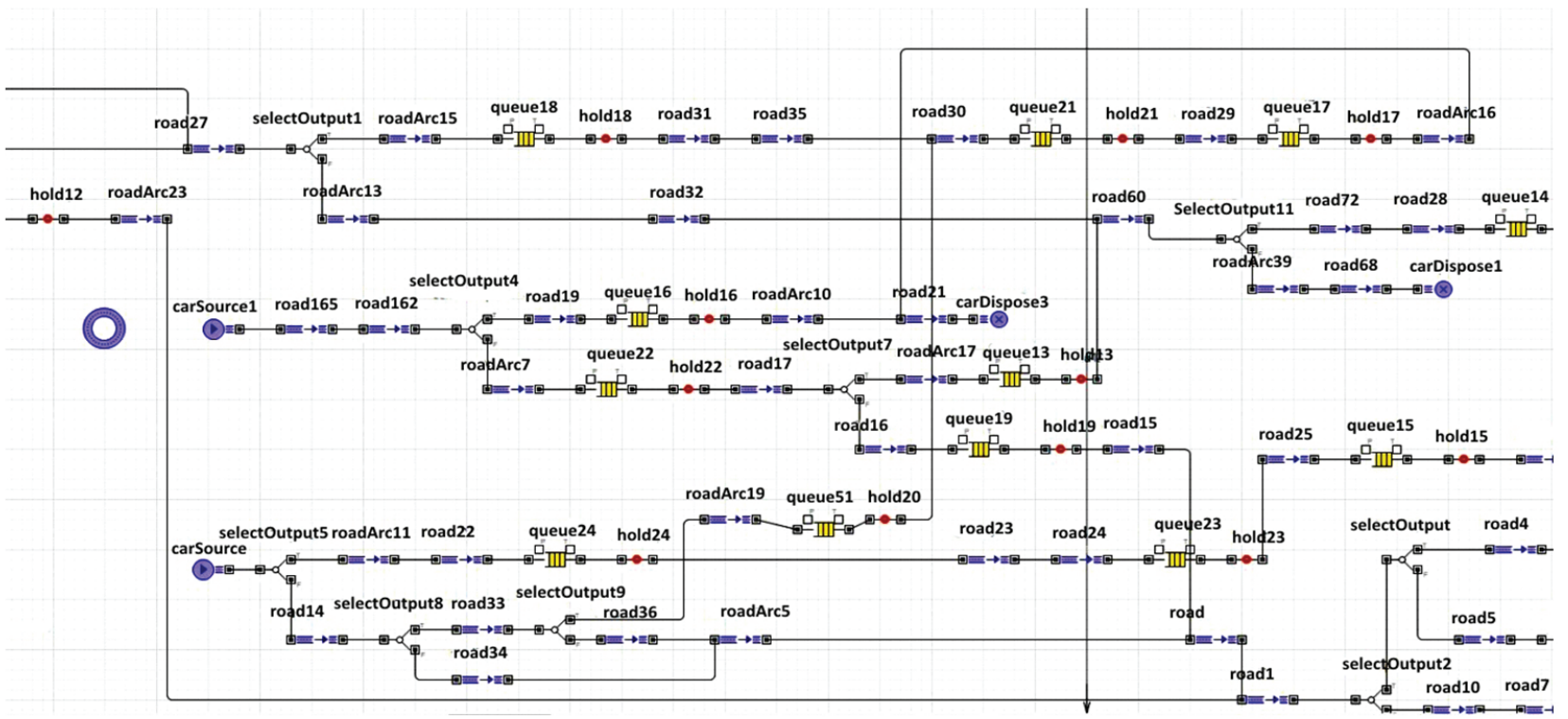

Figure 9: Circuit model of the organization of traffic on the site

The vehicles behaviour on the road was modeled using a Java class "Car".

The Road Network block assigns the maximum speed of vehicles, swivel and U-turn speed, maximum and minimum distance to the vehicle in front, and the distance and time to for warning of rearrangement. Another parameter taken into account is gear changing at different road segments. It is estimated by assigning a speed value in the Car Move To block. Transport current is generated using Car Source blocks.

In the model, cars are moving in keeping with movement parameters set in Car Move To blocks. Distributing of the traffic in different di- 
rections occurs in Select Output blocks. Queue modeling at traffic lights, crossroads and U-turns is performed using Queue blocks. Hold blocks simulate the operation of traffic lights and traffic control at road curves and U-turns. The motion of public transport is simulated by Delay blocks specifying delays at bus stops. Traffic lights and traffic motion at U-turns are controlled using state diagrams.

\section{OPTIMIZATION EXPERIMENTS IN THE MODEL}

Simulation of traffic parameters established as a result of field observations has made it clear that congested traffic produces carbon monoxide and nitrogen dioxide by far exceeding the ACL levels (Figure 10). The optimization experiment on a simulation model was carried out using an OptQuest device and metaheuristic methods. At the first stage of the experiment, we determined the optimal parameters for the traffic current, such as density, intensity and speed, falling within the quota for pollutant emissions (Figure 11).

Representing a confluence of two main city avenues, the site in question accommodates several public transport routes connecting the city's newer and older parts. Therefore optimizing of the traffic current parameters should primarily involve improving of the route network. Another approach consists in using of buses with greater capacity, which will both diminish the traffic current density and reduce emissions of harmful substances. Similar methods are described in works. [07, 11, 12]

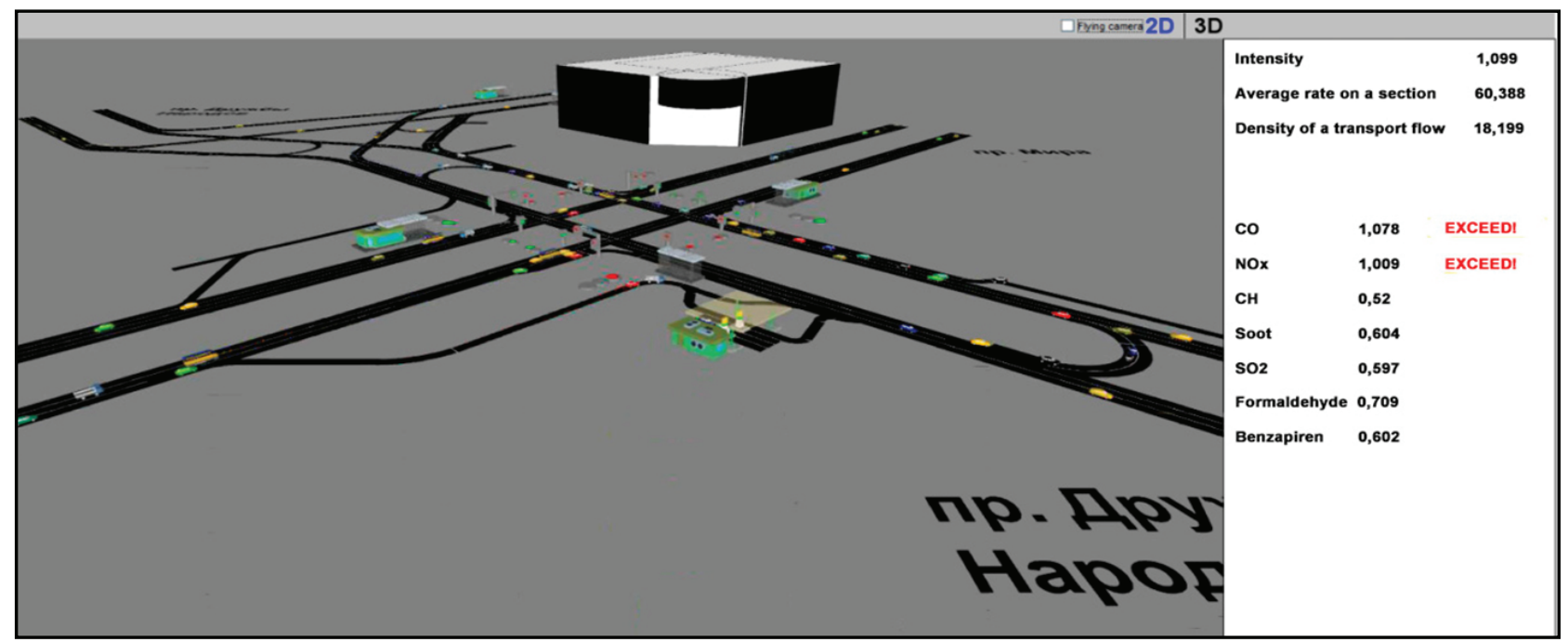

Figure 10: The view of the simulation model of the considered section of the road network

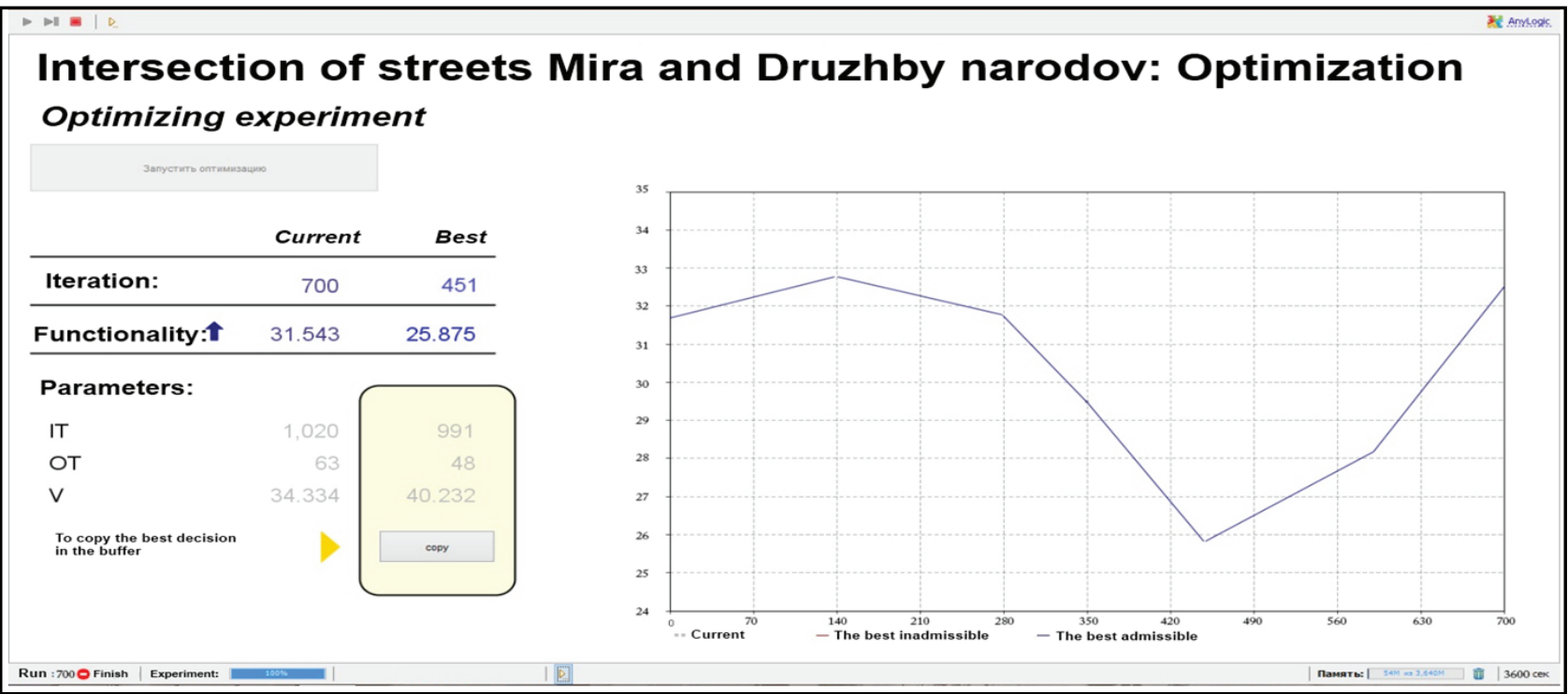

Figure 11: Optimization experiment 
At the second stage of optimization experiment there were determined the vehicular emissions. While preserving the original parameters, we replaced a part of the public transport with more environmentally friendly vehicles. This considerably reduced the volumes of emitted pollutants.

\section{CONCLUSION}

The proposed solution for improving the quality of ambient air in urban areas is based on optimization of a city transport system parameters. This was achieved by via simulation modeling taking into account a large number of parameters, both within and outside the system, many of the latter being stochastic. The model has been tested using the simulation model analysis of part of a road network and comparing the results with real system parameters. The recommendations include rearranging of the public transport routes and changing over to vehicles running on gas motor fuel.

\section{ACKNOWLEDGEMENTS}

This work was funded by the subsidy allocated to Kazan Federal University for the project part of the state assignment in the sphere of scientific activities.

\section{REFERENCES}

1) Economic and Social Council. Integration Segment: Sustainable Urbanization. 2014, 1-8.

2) Global Status Report On Road Safety. Time For Action. World Health Organization. 2009, 287.

3) Horton, B.; Ulrich Speck, S. Green Economy. Europe's environment: An Assessment of Assessments; Publication Ofiice of the European Union: Luxembourg, 2011; 92-138.

4) Hygienic requirements for air quality residential areas. Sanitary - epidemiological rules and norms. SanPin 2.1.6.98300; Russian Ministry of Health: Moscow, 2000; 47.

5) Makarova, I.; Khabibullin, R.; Belyaev, E.; Zhdanov, D. Intellectualization of transport systems for the benefit of safety and the sustainable development of territories. Journal of International Scientific Publications: Ecology\&Safety. 2013, 7(3), 189-199.

6) Molina, Mario J.; Molina, Luisa T. Megacities and Atmospheric Pollution. Journal of the Air \& Waste Management Association. 2004, 54(6), 644-680.

7) Naoto, M.; Watanabe, T.; Feng, J. Route Optimization Using Q-Learning for On-Demand Bus Systems. Knowledge-Based Intelligent Information and Engineering Systems. 2008, 5178, 567-574.

8) OND-86. Method of calculating the concentrations in the air of harmful substances contained in industrial emissions; Gidrometeoizdat: Leningrad, 1987; 35.

9) Petruhin, V.; Vazhensky, V.; Donchenko, V. Pollution of urban atmosphere by vehicles and environmental risks to public health: methodology and experience ratings / Transport: science, technology, management. 1996, 9. 33-35.

10) Reich, Alicia A. Transportation Efficiency. Strategic Planning for Energy and the Environment. 2012, 32(2), 32-43.

11) Saharidis, G.K.D.; Dimitropoulos, C.; Skordilis, E. Minimizing waiting times at transitional nodes for public bus transportation in Greece. An International Journal "Operational Research”. 2013, 14(3), 341-359.

12) Shimamoto, H.; Murayama, N.; Fujiwara, A. Evaluation of an existing bus network using a transit network optimisation model: a case study of the Hiroshima City Bus network. Transportation. J. 2010, 37(5). 801-823.

13) The general plan of the city of Naberezhnye Chelny: Materials on the study of the project. Explanatory note. Tatinvestgrazhdanproekt: Kazan, 2009, 140.

Paper sent to revision: 19.01.2015.

Paper ready for publication: 09.03.2015. 